\title{
Ophthalmologische Gesellschaft zu Berlin
}

\section{Sitzung vom 19. Oktober 1905}

Vorsitzender: Herr v. Michel. Schriftführer: Herr Wertheim.

Herr v. Michel eröífhet diese erste Sitzung nach den Ferien mit einem warm empfundenen

Nachruf an Carl Schvveigger. Die Yersammlung driickt ihre Trauer urn den Entschlafenen durch Erheben von den Sitzen aus.

Vor der Tagesordnung demonstriert Herr C. Hamburger ein 16jähriges Mädchen, auf dessen einem Auge die Ciliarfortsätze infolgo von gesclirumpfter Katarakt temporal deutlich sichtbar siad.

Herr Perlmann (a. G.): Das Refraktiometer, ein neues Instrument zur Refraktions und Visusbestimmun g. Der Vortragende hat ein Brillengestell konstruiert, das fast den ganzen Brillenkasten in sich vereinigt; die einzelnen Komponenten des (bei D off el \& Färber erhältlichen) Apparates sind sämtlich bekannt. An Stelle der üblichen Gläser uvserer Brillenkasten kommen nur solche von der Grösse der Linsen in unseren modernen Refraktionsaugenspiegeln zur Verwendung, wie denn der Apparat mit seinen doppelten Linsenräderpaaren in dem Ophthalmoskop sein Vorbild hat. Die Linsen können durch eine Schraube ganz dicht an das Auge herangebracht werden, die Pupillendistanz ist gleichfalls dnrch Sehrauben veränderlich, die Kleinheit der Sehlöcher erlaubt gute Zentrierung.

Herr Seeligsohn stellt einen Mann mit primärem papulösem Syphilid des Augenlides vor. Herr Greeff: Über Trematoden im Auge. Der Vortragende gibt eine kurze historische Übersicht über die Erwähnungen von Saugwärmern

512

Therapeutische Umschau.

im Auge und teilt mit, dass er selbst bei viele $\pi$ Fischen in hiesigen Teichen Entozooen der Linse gefunden habe. Die Trematoden finden sich ursprüng-lich im Darm einer bestimmten Art Moven und gelangen mittels der Exkremente in die Teiche. Greeff hat aueh bei einem Fischer die Trematoden in der nicht gehärteten Linse gefunden, die vielleicht die vorhandeae Katarakt hervorgerufen habe.n

Diskussion.

Herr Hirschberg bemerkt, dass er díese Fragen 1870 in seiner Habilitationsschrift behandelt habe, ebenso habe dies Waldenburg 1859 in seiner Dissertation getan. - Das mikroskopische Präparat der menschlichen Linse, das Herr Greeff jetzt selbst als nicht mehr deutlich bezeichnet hatte, scheint ihm auch nicht ganz überzeugend.

Herr Abelsdorff erwähnt noch, dass man oft bei Fischen Linsen-trübnngen findet.

Herr A. Gutmann: Beitrag zurAtiologie und Statistik einer primären Iritis. (1st soeben in der Deutschen med. Wochenschr. gedruckt erschienen.)

Herr v. Michel: Pathologisch-anatomische Mitteilungen. Essind bisher 10 Fälle von Tetanus nach A.ugenverletzungen besehrieben, denen v. Michel jetzt einen elften anreiht. In 3 Fallen war eine Panophthalmieeingetreten, $5 \mathrm{mal}$ hatte es sich urn Verletzung des Orbital/,ellgewebes gehandelt. Im vorliegenden Falle eines 18jährigen Knaben war die Verletzungdes Orbitalgewebes 
durch einen Bambusstock erfolgt. Ophthalmoskopischzeigte sich der typische Befund des Verschlusses der Art. centr. retinae. -Nach der Verletzung trat bald Erbrechen, Exophthalmus und Trismus ein.Bei der Exenteratio orbitae fand sich noch ein klein $\beta$ s Stuck Holz in derFissura orbitalis superior, die Dura aber war normal. 5 Tage nach derLäsion plötzlich Exitus. Ein injiziertes Meerschweinchen ging prompt anTetanus zugrunde. - Bei der Sektion zeigte sich eine Blutung im TenonschenRaum, die den Exophthalmus verursacht hatte, im Subduralraum eineEiterung. Mikroskopische Schnitte (die auch demonstriert werden) ergabenVerschluss der Arterie durch Ablös $\pi$ ng der Intima. (Querdurchtrennung desGefässes!) Pollack. Therapeutische Umschau.

Méthode simple, de choix, pour l'opération de certaines formes de chalazioП. Von Antonelli. La clinique ophtalmologique. XI. Jahrg. No. 13.

D. Die ,intermarginale Incision” bei Chalazien die Agnew 1888 empfahl bringt Antonelli in Erinnerung für Chalazien im Unter-lid und solche nahe dem freien Lidrand im Oberlid. Er empfiehlt das Einstechen eines zweischneidigen Messerchens gerade in der Linie der Mündungen der Meibomschen Drüsen

zwischen Tarsal- und Hautteil des Lides oder durch die Dicke des Tarsus selbst unter Kontrolle der Finger der anderen Hand dann seitliche Bewegungen des Instrumentes nasal und temporal wenn die Messerspitze bis jenseits der Grenze des Chalazions angekommen ist um auf diese Weise den ganzen von der Neubildung eingeđommenen Bezirk parallel der Hautoberfläche zu 